\title{
Fantastic Pirates: software de apoio ao ensino e a aprendizagem infantil
}

\author{
Caio Almeida Abreu ${ }^{1}$, Jean C. S. Rosa ${ }^{2}$, Ecivaldo Matos ${ }^{2}$ \\ ${ }^{1}$ Escola Politécnica - Universidade Federal da Bahia (UFBA) \\ Rua Prof. Aristides Novis, 02, Federação - Salvador - BA - Brasil \\ ${ }^{2}$ Departamento de Ciência da Computação - Universidade Federal da Bahia (UFBA) \\ Av. Adhemar de Barros, s/n, Ondina - Salvador - BA - Brasil \\ caioabreu@outlook.com, \{jean.rosa, ecivaldo\}@ufba.br
}

\begin{abstract}
Resumo. O mercado de aplicativos móveis educacionais apresenta uma gama diversificada de opções destinadas à satisfação de diversos públicos, sobretudo o infantil. No entanto, parte considerável desses aplicativos abrange diversas idades e desconsidera características intrínsecas à educação infantil, em que crianças têm necessidades de interação diferenciadas e necessidades educacionais especificas. Este artigo apresenta dois protótipos de aplicativos móveis, o Fantastic Pirates, destinado às crianças de até 10 anos de idade, e um aplicativo de suporte, destinado aos educadores (professores e responsáveis), o Fantastic Pirates Educator.
\end{abstract}

Abstract. The marketplace of educational mobile applications presents a diverse range of options aimed at the satisfaction of different audiences, especially children. However, a considerable part of these applications covers various ages and disregards the intrinsic characteristics to early childhood education, in which children have different interaction needs and special educational needs. This paper presents two mobile application prototypes, the Fantastic Pirates, aimed at children up to 10 years old, and a support application for educators, the Fantastic Pirates Educator.

\section{Cenário de uso}

O software Fantastic Pirates (FP) é produto de um projeto de pesquisa cujo objetivo é apresentar um conjunto de heurísticas de usabilidade específico para aplicativos móveis educacionais infantis. Esse conjunto baseia-se na adaptação das heurísticas de usabilidade para o domínio de aplicativos móveis educacionais de Barbosa, Oliveira e D'Carlo (2016), analisadas a partir dos elementos caracterizadores do domínio infantil, indicados por An et al. (2013) e Gomes et al. (2015), além da proposição de novas heurísticas.

O protótipo do aplicativo FP foi desenvolvido sob a perspectiva dessas heurísticas. Neste contexto, o FP considera aspectos como: uso do lúdico, afetividade, motivação, linguagem destinada ao público alvo, feedback construtivo. Desse modo, o FP e o Fantastic Pirates Educator (FPE), desenvolvidos para Android, visam, juntos, reduzir o problema da carência de aplicativos desenvolvidos sob a perspectiva pedagógica, considerando as necessidades educacionais e de interação específicas à 
VI Congresso Brasileiro de Informática na Educação (CBIE 2017)

Anais dos Workshops do VI Congresso Brasileiro de Informática na Educação (WCBIE 2017)

educação infantil (An et al., 2013). Os aplicativos propostos podem ser utilizados tanto em ambiente escolar quanto doméstico.

$\mathrm{O}$ aplicativo FP destina-se às crianças de até 10 anos (educação infantil e os primeiros anos do ensino fundamental). Por meio do FPE, educadores (professores e responsáveis) podem criar quizzes entre 5 e 30 questões. $\mathrm{O}$ educador tem flexibilidade para criar suas próprias perguntas, possibilitando a abrangência de quaisquer disciplinas. Devido a essa flexibilidade, professores e responsáveis podem também desenvolver questões destinadas a temas difíceis de serem trabalhados com crianças, tais como o combate à corrupção ou bullying, por exemplo. Ao final de cada questão, o educador deve indicar um feedback construtivo, o qual colaborará com a aprendizagem da criança. Ao término da criação de um quiz, o educador pode compartilhá-lo com a criança via qrcode ou outros meios disponíveis.

O aplicativo FP, por outro lado, abrange características de jogos educacionais infantis, especialmente ao fazer uso do lúdico sob o tema de piratas. Desse modo, a criança acessa o quiz compartilhado pelo educador em formato de jogo. As perguntas são apresentadas como "mapas do tesouro" e a pontuação como "moedas de ouro". A criança acumula dicas a cada questão respondida. Essas dicas são apresentadas por um personagem do jogo (pirata), juntamente com o feedback de cada questão. Ao final do jogo, dois relatórios, um de desempenho da criança no quiz e outro com as respostas erradas da criança, são enviados ao educador.

Esses resultados podem ser acessados por meio do aplicativo de suporte ao educador, o FPE. Por meio do FPE, o educador pode visualizar gráficos de desempenho relacionados aos acertos da criança no quiz, como também gráficos que apresentam um comparativo entre o desempenho de todas as crianças que realizaram aquele quiz. Como crianças podem ter necessidades de aprendizagem individuais, o relatório recebido pelo educador contém todas as questões que a criança errou em um determinado quiz, bem como todas as alternativas erradas marcadas por ela. Desse modo, o educador pode trabalhar as dificuldades pedagógicas individuais de cada criança.

A Figura 1 apresenta o cenário de uso dos softwares FP e FPE. Nesse cenário, o educador cria um quiz no aplicativo FPE e o compartilha via qrcode ou outros meios (Whatsapp, email, Facebook). Supondo-se que o compartilhamento seja efetuado via qrcode, o aplicativo FP possui um leitor de qrcode embutido (botão branco localizado na segunda tela da Figura 1) que possibilita a leitura da chave do jogo (código do quiz) sem a necessidade de a criança digitar essa chave. A partir desse contexto, a criança tem acesso ao quiz e pode jogar.

Para promover a inclusão de portadores de deficiência visual, foi desenvolvido um modo de acessibilidade exclusivamente para o aplicativo FP. Esse modo de acessibilidade visa auxiliar crianças cegas ou com deficiência visual. Ao ser acionado, esse modo torna visível um ícone de acessibilidade localizado em posição fixa em todas as telas do jogo. Ao tocar nesse ícone, o aplicativo narra antecipadamente a tela atual e fornece informações sobre os próximos passos para que a criança possa proceder no jogo. Esse modo também pode ser utilizado com objetivo de auxiliar crianças que estão em processo de alfabetização, visto que a narração textual pode auxiliar a compreensão das crianças sobre aquilo que está escrito em determinado cenário. 
VI Congresso Brasileiro de Informática na Educação (CBIE 2017)

Anais dos Workshops do VI Congresso Brasileiro de Informática na Educação (WCBIE 2017)

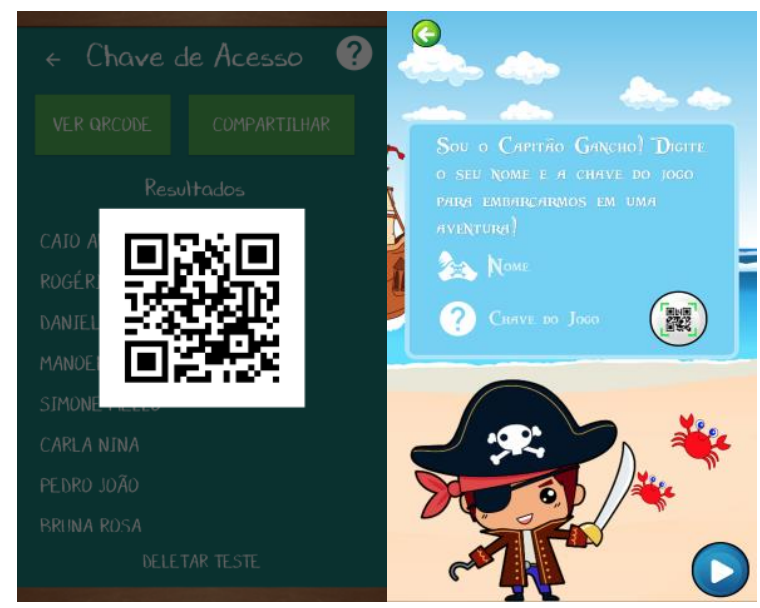

Figura 1. Qrcode (chave de acesso ao quiz) no FPE e tela de acesso ao quiz no FP

Para os deficientes visuais, recomenda-se utilizar o modo de acessibilidade juntamente ao talkback ${ }^{1}$, visto que aquele permite narração antecipada da tela, enquanto que esse narra apenas os elementos que são tocados pelo usuário.

\section{Desenvolvimento}

Para o processo de desenvolvimento do software foi realizado um levantamento de requisitos funcionais e não funcionais. Os requisitos apresentados tiveram origem nas heurísticas de usabilidade para aplicativos móveis educacionais infantis, dos conhecimentos dos pesquisadores e da observação de aplicativos educacionais na Google Play², especialmente aqueles destinados ao público infantil. Também foram desenvolvidos diagramas de caso de uso dos softwares, diagramas de atividades para casos de uso específicos, especificações dos principais casos de uso, como também protótipos de baixa e alta fidelidade das telas dos aplicativos.

Os protótipos foram desenvolvidos para smartphones. O sistema operacional escolhido foi o Android, da empresa Google. A escolha desse sistema se deu pela análise dos dados da Kantar Worldpanel ${ }^{3}$, empresa multinacional especializada no comportamento de compradores. Os dados dessa empresa, coletados em 2017, revelam que $92,1 \%$ dos smartphones no Brasil utilizam o sistema operacional Android. Os testes foram realizados no dispositivo móvel Nexus 6, cuja resolução da tela é de 2560x1440 pixels. Portanto, os protótipos se adequam a essa resolução de tela, podendo haver ajustes imprevistos para dispositivos com resoluções de tela distantes da que foi testada. Desse modo, layouts para outras resoluções de tela serão desenvolvidos como trabalho futuro. Os protótipos foram projetados sob a versão mínima de API 15, portanto são compatíveis com 99\% dos dispositivos Android ativos em 2017, segundo dados da

\footnotetext{
${ }^{1}$ Serviço de acessibilidade do Android que auxilia deficientes visuais na interação com seus dispositivos.

${ }^{2}$ Loja de aplicativos da empresa Google.

${ }^{3}$ https://www.kantarworldpanel.com/global/smartphone-os-market-share/
} 


\section{Google ${ }^{4}$.}

Para a implementação dos aplicativos, foi utilizada a linguagem de programação Java, por ser a linguagem padrão para o desenvolvimento de software em Android. O ambiente de programação utilizado foi o Android Studio, desenvolvido pela Google. Também utilizou-se a linguagem $\mathrm{XML}^{5}$ para desenvolver os layouts das telas dos aplicativos. Essa linguagem foi utilizada dentro do Android Studio, o qual fornece uma ferramenta de visualização gráfica das telas.

O back-end do aplicativo utilizou a plataforma Firebase, também da Google. O Firebase é um $\mathrm{BaaS}^{6}$ que fornece diversos serviços baseados na nuvem em que os desenvolvedores móveis podem usar para aprimorar as suas aplicações. Os serviços utilizados foram o banco de dados não-relacional (NoSQL) e a transferência de dados entre o aplicativo e o Firebase. No banco de dados não-relacional foi utilizada uma formatação leve de troca de dados, denominada JSON (Notação de Objetos JavaScript).

O aplicativo FP está sobre processo de avaliação de interação por meio de crianças, responsáveis, especialistas em Interação Humano-Computador e psicopedagogos. Mediante as avaliações, os pesquisadores buscam encontrar problemas de usabilidade por meio da inspeção heurística, com heurísticas específicas para aplicativos móveis educacionais de domínio infantil, e a técnica think-aloud (Markopoulos et al., 2008).

\section{Apresentação do Software}

Ao iniciar o aplicativo FP, o software apresenta à criança a tela inicial do jogo, representada pela Figura 2 (tela à esquerda). Nessa tela, a criança pode realizar ajustes no jogo, por meio do botão amarelo, localizado no canto inferior esquerdo da tela, ou prosseguir no jogo, por meio do botão azul, localizado ao centro da tela.

Caso a criança opte por realizar ajustes, o aplicativo apresenta a tela representada na Figura 2 (tela ao centro). Nessa tela, o usuário pode controlar a música de fundo, os sons do jogo e um modo de acessibilidade destinado a deficientes visuais ou crianças em processo de alfabetização que apresentem dificuldades de leitura. $\mathrm{O}$ modo de acessibilidade faz a narração antecipada da tela, facilitando ao usuário identificar os elementos presentes na tela e adquirir informações sobre as próximas ações para prosseguir no jogo.

Para prosseguir no jogo, a criança será guiada para a tela representada na Figura 2 (tela à direita). Nessa tela a criança deve indicar seu nome e inserir a chave do jogo (código para acessar o quiz criado pelo educador). A chave pode ser copiada e colada no campo "chave do jogo" ou a criança pode tocar no botão branco, localizado ao lado desse campo, e apontar a câmera do smartphone para o qrcode ${ }^{7}$ apresentado por um educador. Ao identificar o qrcode, o software preenche o campo "chave do jogo"

\footnotetext{
${ }^{4}$ https://developer.android.com/about/dashboards/index.html

5 eXtensible Markup Language

${ }^{6}$ Backend as a Service

${ }^{7}$ O educador deve, previamente, criar um quiz no aplicativo FPE e fornecer o qrcode desse quiz para a criança acessá-lo no aplicativo FP.
} 
VI Congresso Brasileiro de Informática na Educação (CBIE 2017)

Anais dos Workshops do VI Congresso Brasileiro de Informática na Educação (WCBIE 2017)

automaticamente. Desse modo, a criança deve tocar no botão azul, localizado no canto inferior esquerdo da tela, para prosseguir no jogo. O aplicativo, em background, faz download das questões do quiz criado pelo educador e automaticamente as redistribui em mapas do tesouro.

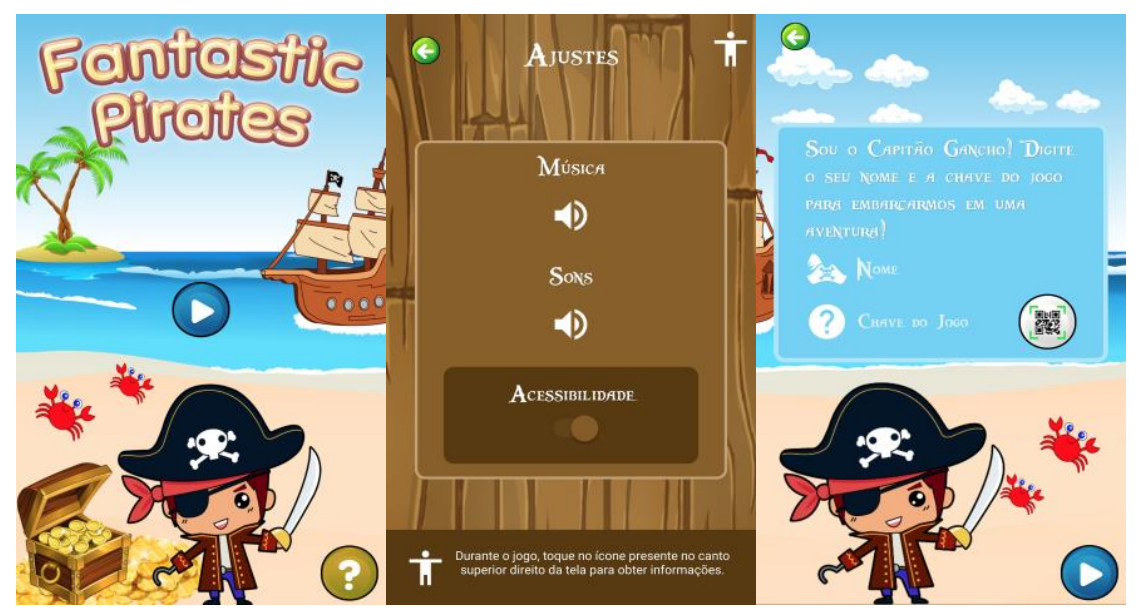

Figura 2. Tela inicial, tela de ajustes e tela de entrada no jogo do aplicativo FP

Cada pergunta representa um mapa. Em seguida são apresentadas telas em que uma animação do personagem pirata interage com a criança explicando $o$ funcionamento do jogo e a envolvendo no ambiente lúdico (Figura 3, tela à esquerda). $\mathrm{O}$ personagem explica que o objetivo do jogo é acumular moedas de ouro e para tal, a criança deve tentar acertar as perguntas dos mapas do tesouro (Figura 3, tela ao centro). Ao responder uma pergunta, a criança receberá feedback instantâneo (Figura 3, tela à direita), mesmo que erre ou acerte, e cada feedback apresenta uma dica para que a criança tente adivinhar a chave de um baú secreto ao final de um ciclo de 5 questões.

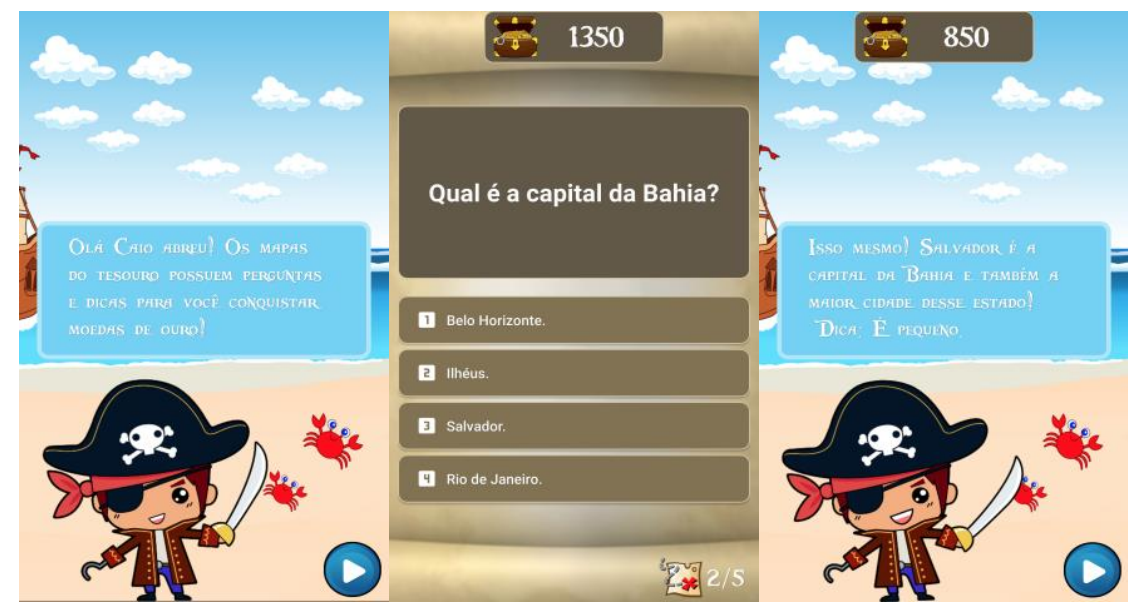

Figura 3. Apresentação do enredo, mapa do tesouro e feedback construtivo

Há ainda a apresentação de subjogos, relacionados ao tema de pirata e alocados pelo algoritmo do jogo, como a "Roleta Mágica" (Figura 4, tela à esquerda) ou o "Baú 
VI Congresso Brasileiro de Informática na Educação (CBIE 2017)

Anais dos Workshops do VI Congresso Brasileiro de Informática na Educação (WCBIE 2017)

Secreto" (Figura 4, tela à direita). Esses subjogos aumentam as chances das crianças ampliarem sua pontuação no jogo, por meio de tesouros que podem ser adquiridos e convertidos em moedas de ouro.

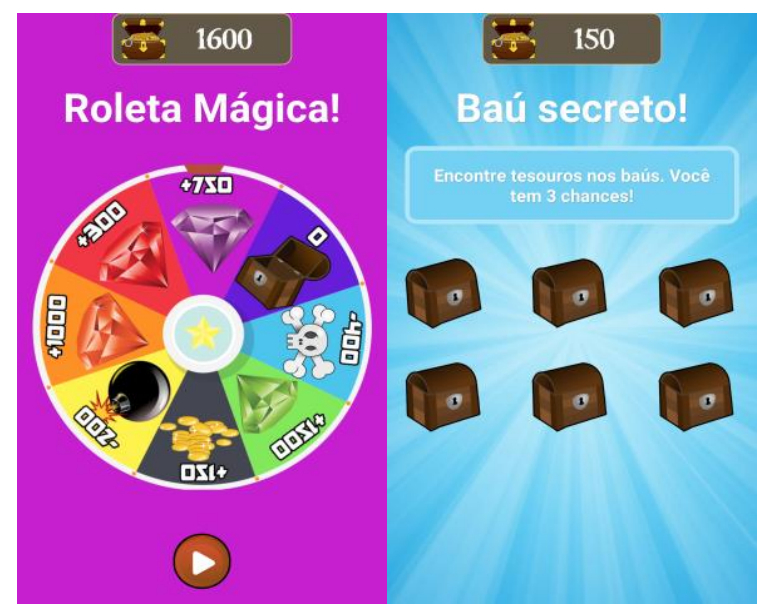

Figura 4. Subjogos da "Roleta Mágica" e do "Baú Secreto"

Ao final de um ciclo de 5 questões, o jogo apresenta uma tela em que o pirata questiona a criança se ela conseguiu descobrir a chave do baú por meio das dicas acumuladas durante o jogo (Figura 5, tela à esquerda). A fim de evitar esforço cognitivo excessivo, caso a criança não lembre das dicas, ela pode tocar no botão amarelo ao lado do campo "chave do baú" para vê-las (Figura 5, tela ao centro). Ao adivinhar o objeto por meio das dicas, a criança deve inserir o nome desse objeto no campo "chave do baú" e prosseguir por meio do botão no canto inferior direito da tela. Caso a criança acerte, o baú será aberto e ela receberá moedas de ouro como premiação.

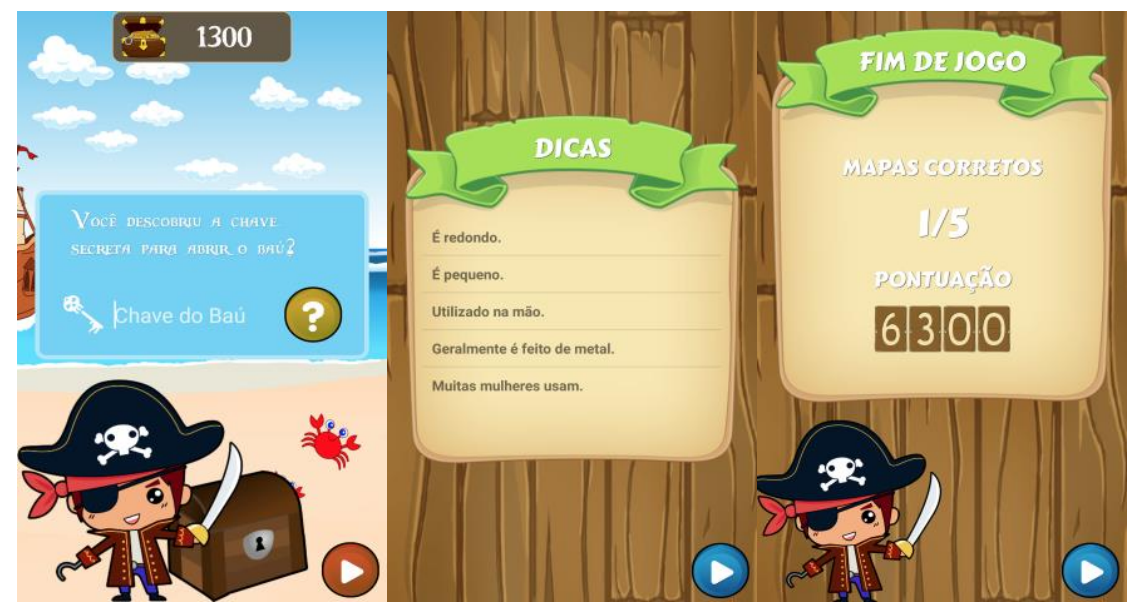

Figura 5. Adivinhação da "chave do baú", dicas e tela de fim de jogo

É importante destacar que ao tocar nos ícones presentes ao lado esquerdo de algum campo de texto, como o chapéu branco ou a interrogação na Figura 2 (tela à direita) ou ainda como a chave branca na Figura 5 (tela à esquerda), o aplicativo lança 
uma janela pop-up contendo ajuda, documentação e informações específicas sobre aquele campo de texto e as próximas ações necessárias para prosseguir no jogo.

Ao final do jogo, o aplicativo apresenta uma tela contendo a quantidade de mapas que a criança acertou e sua pontuação no jogo (Figura 5, tela à direita). Em background, os resultados são enviados para o aplicativo de suporte (FPE), destinado ao educador. Os resultados contêm o desempenho individual da criança no jogo (Figura 6, tela à esquerda), um comparativo de desempenho entre todas as crianças que jogaram o mesmo jogo (Figura 6, tela ao centro), como também um relatório contendo todas as questões que a criança errou e todas as alternativas erradas que ela escolheu (Figura 6, tela à direita). Desse modo, o educador pode entender as dificuldades específicas de cada criança e trabalhá-las de maneira individual e personalizada.

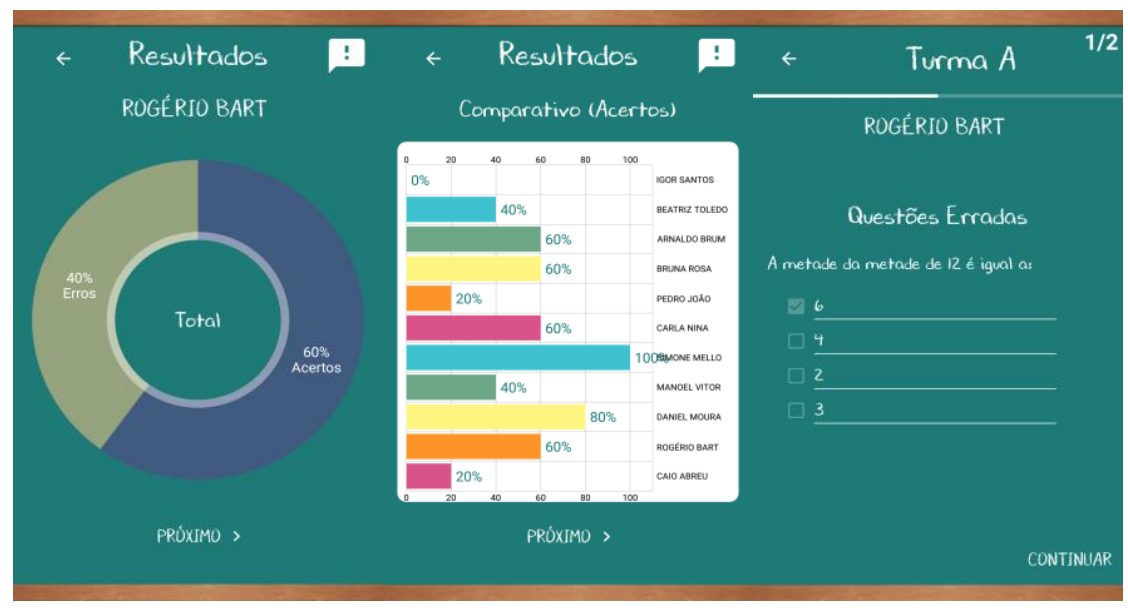

Figura 6. Telas de resultados e relatório de erros do software destinado ao educador - FPE

A licença de uso para os softwares ainda se encontra sob análise. O vídeo demonstrativo pode ser acessado via Youtube através do seguinte link: https://www.youtube.com/watch?v=jpnSNAXeVjI.

\section{Considerações finais}

O aplicativo FP destina-se às crianças de até 10 anos (educação infantil e os primeiros anos do ensino fundamental). Por meio do FPE, os educadores (pais e professores) podem desenvolver suas próprias perguntas e criar feedback construtivo que auxilia na aprendizagem da criança. Desse modo, os educadores têm a flexibilidade de aplicar quizzes multidisciplinares, questionando a criança não apenas assuntos relacionados à escola, como matemática, geografia, português, mas também perguntas relacionadas às questões éticas, tais como: corrupção, bullying e outros temas tão difíceis de serem trabalhados no cotidiano infantil. O nível de dificuldade das questões, portanto, é também estabelecido pelo próprio educador. Essa flexibilidade permite que crianças de diferentes idades possam fazer uso do aplicativo destinado à elas. Vale ressaltar que os aplicativos se aplicam tanto ao ambiente escolar quanto ao ambiente familiar.

O aplicativo FP apresenta um ambiente agradável, abordando o uso do lúdico em todo seu tema, especialmente na apresentação das perguntas, criadas pelos 
educadores no FPE, e que são apresentadas no FP como mapas do tesouro. Desse modo, a criança sente-se envolvida com o ambiente. Ao final do jogo, o FP envia um relatório contendo o desempenho que a criança obteve no jogo, baseado no número de questões respondidas corretamente, e um relatório que aponta todas as questões que a criança errou, como também as alternativas selecionadas por ela nessas questões erradas. Esses dados podem ser observados pelos educadores no aplicativo FPE. Consequentemente, responsáveis e professores podem compreender melhor as dificuldades das crianças e trabalhar individualmente com cada uma delas. Um dos destaques do software é que as crianças não têm conhecimento de que estão sendo "testadas", pois o ambiente do aplicativo FP apresenta uma perspectiva de jogo, mas com propósito educacional. Outro destaque é a possibilidade do educador criar quantos quizzes ele quiser e estar constantemente avaliando a criança de maneira interativa e divertida.

A validação de ambos aplicativos encontra-se em fase de execução, portanto ainda não há análise dos dados coletados até o presente momento. Como projeto futuro, espera-se ampliar a quantidade de subjogos do FP; as premiações; e desenvolver novas funcionalidades, tais como permitir que o educador possa trocar sua senha ou email de cadastro no aplicativo FPE. Espera-se ainda desenvolver layouts para múltiplas resoluções de tela, adicionar suporte multilíngue e reajustar os possíveis problemas que podem ser encontrados no processo de validação dos aplicativos com as heurísticas de usabilidade. Por fim, na perspectiva empreendedora, planeja-se desenvolver um modelo de negócios, utilizando uma ferramenta de planejamento estratégico, como por exemplo o Canvas ${ }^{8}$, e estudar a viabilidade de monetização dos softwares.

\section{References}

An, D. Y.; Silva, C. D.; Ribeiro, D. M. G.; Rocha, P. B. R.; Maltini, C.; Nunes, V. B.; Fávero, R. (2013) "Digita - Um jogo educativo de apoio ao processo de alfabetização infantil”. In: Anais do XXIV Simpósio Brasileiro de Informática na Educação, p. 154-163.

Barbosa, G.; Oliveira, E.; D’Carlo, D. (2016) "Usabilidade em aplicativos móveis educacionais: Um conjunto de heurísticas para avaliação". In: Anais do XXVII Simpósio Brasileiro de Informática na Educação, p. 777-786.

Gomes, T. C. S.; Barreto, P. P.; Lima, I. R. A.; Falcão, T. P. (2015) "Avaliação de um jogo educativo para o desenvolvimento do pensamento computacional na educação infantil". In: Anais dos Workshops do IV Congresso Brasileiro de Informática na Educação, p. 1349-1358.

Markopoulos, P.; Read, J. C.; MacFarlane, S.; Höysniemi, J. (2008) "Evaluating Children's Interactive Products: Principles and Practices for Interaction Designers”. Morgan Kaufmann Publishers Inc.

\footnotetext{
${ }^{8}$ Business Model Canvas
} 